\title{
Homeless people preserved former identities, devalued current identities, and envisioned a non-homeless future
}

Boydell KM, Goering P,Morrell-Bellai TL. Narratives of identity: re-presentation of self in people who are homeless. Qual Health Res 2000 Jan;10:26-38.

\section{QUESTION: What is the lived experience of homelessness?}

Design

Qualitative study using an interactionist analysis of the human lived experience.

Setting

Toronto, Ontario, Canada

\section{Participants}

29 single adults (age range $18-61$ y, $70 \%$ men) who used homeless shelters. More than half (52\%) had never been homeless before.

\section{Methods}

Semistructured, individual interviews of 45 minutes to 2.5 hours were held in hostels, coffee shops, or the researchers' offices. The interview guide was based on the findings from a focus group of 8 homeless people. Interviews were audiotaped and transcribed verbatim. Interviewer field notes were also transcribed. Analysis was based on a participatory team approach.

\section{Main findings}

Homelessness created identity problems for the participants, whereby positive former identities were preserved, current identity was devalued, and future identities were glimpsed.

In terms of the past self, homelessness meant the loss of an established identity on 2 levels: reduced access to entitlements (because of the lack of a permanent address) and the psychological loss of a sense of identity. Participants, however, showed pride in their former identities that were now lost to them.

In terms of the present self, participants who were homeless for the first time presented themselves in a positive way, often describing themselves as honest, loveable, and hardworking. Many chronically homeless participants tended to put themselves down, saying that they were unreliable, unaccomplished, and irresponsible. Participants spoke of a devalued self, which was reinforced through interactions with others during their daily lives in shelters and on the streets. Participants often described themselves as different from and better than other homeless people; in effect, they created, in their minds, an identity hierarchy within the ranks of the homeless. They felt that they were not as bad, as lazy, or as unmotivated as other homeless people were, and they noted the lack of many of the characteristics often associated with homelessness (eg, drug use, spousal abuse, or mental illness).

In terms of the future self, many participants talked of a future that included a non-homeless identity, and some thought that they might like to become involved in helping other homeless people. Some felt that experiencing homelessness gave them a deeper understanding of the meaning of life, which resulted in a wisdom that transcended the former self.

\section{Conclusions}

Homelessness posed a threat to identity as a result of the loss of "...the accoutrements (meaningful work, relationships, and a place to call one's own) that are critical to helping individuals define themselves"(p35). Homeless individuals felt devalued, and coped by creating an identity hierarchy, whereby they put themselves at the top of the homeless strata. They talked about a future self involved in meaningful work, strengthened by the homeless experience.

\section{COMMENTARY}

The qualitative study by Boydell et al offers a fresh look at the concept of self identity among a marginalised group of homeless adults. Society often stereotypes homeless people as passive, lazy, disaffiliated, and disempowered. ${ }^{1}$ These researchers provide evidence that although many homeless adults have lost much of their sense of self as worthy and competent, they are still engaged in self reflection. This capacity for self reflection can have a healing effect in the face of threat and loss; by beginning with self awareness, health and wellbeing can be enhanced through self reflection. ${ }^{2}$

The findings that homeless adults strive to have valued lives and selves were based on interviews with individuals who were comfortable talking about their experience of homelessness and who could recall details about the year before they became homeless. With this rather stringent definition of "homeless adults," the findings may not apply to the larger population of homeless people. It is possible that these participants had already engaged in serious self reflection and may have rated themselves more highly than other homeless people because they viewed their situation as temporary and not a reflection of their true identity.

Despite this limitation, the findings provide important information about self identity among homeless adults. Those who were newly homeless described themselves in positive terms (eg, moral and hardworking), whereas those who were chronically homeless described themselves in more negative terms (eg, unreliable and irresponsible). The evidence provided by the study suggests that interventions to help homeless individuals need to take place as soon as is feasible in the chronology of homelessness. Such interventions could be directed toward preserving the positive identities of these individuals and exploiting past and future identities of the self as competent. Future research is now needed to design and evaluate interventions that aim to achieve these goals.

Lynn Rew, RN, EdD Professor and Graduate Advisor, School of Nursing The University of Texas at Austin Austin, Texas, USA

1 Cohen MB, Wagner D. Acting on their own behalf: affiliation and political mobilization among homeless people. J Sociol Soc Welf 1992;19:21-40.

2 Rew L. Self-reflection: consulting the truth within. In Dossey BM, Keegan L, Guzzetta CE, editors. Holistic nursing: a handbook for practice. Third edition. Gaithersburg, MD: Aspen Publishers, 2000:407-23. 